\title{
La posibilidad de implantar un estándar ético en la empresa periodística española: percepción de los directivos de los medios
}

\author{
Carlos MAcIÁ-BARBER \\ Universidad Carlos III de Madrid \\ carlos.macia@uc3m.es
}

Recibido: 5 de diciembre de 2014

Aceptado: 8 de mayo de 2015

\section{Resumen}

En la actualidad, la imagen de las empresas se relaciona con aspectos éticos y sociales de sus actuaciones, además de ligarse a los resultados financieros. El objeto del presente estudio es valorar la posibilidad de instaurar un específico estándar ético en los medios de comunicación españoles, conforme a la percepción de los directivos de relevantes corporaciones mediáticas por tamaño y por difusión (prensa, radio, televisión y medios digitales). Durante las entrevistas en profundidad $(\mathrm{n}=30)$ y los grupos de discusión $(n=3)$, los directivos muestran posturas enfrentadas sobre el interés e implantación de la propuesta, sensibles divergencias sobre quién se encargaría de establecer el modelo y supervisar su funcionamiento, así como sobre las variables básicas a evaluar. Por su parte, periodistas encuestados al respecto $(n=420)$ consideran que una iniciativa de esta naturaleza tendría sentido (6,4 sobre 10$)$.

Palabras clave: Ética, periodismo, estándar, empresa informativa, España.

\section{The possibility of implement an ethical standard in the Spanish media: the perception of the management staff members}

\begin{abstract}
Today, the image of companies relates to ethical and social aspects of their actions, as well as connects to financial results. The aim of this study is to assess the possibility of establishing a specific ethical standard in the Spanish media, according to the perception of the executives of the most relevant media corporations by size and circulation (press, radio, television and digital media). The in-depth interviews $(n=30)$ and focus groups $(n=3)$ show managers opposing positions on interest and implementation of this self-regulation proposal, a wide divergence over who is responsible for establishing and supervising the model, and to evaluate the basic variables. Meanwhile, journalists surveyed about $(n=420)$ believe that an initiative of this nature would make sense (6.4/10).
\end{abstract}

Keywords: Ethics, Journalism, Standard, Media, Spain.

\section{Referencia normalizada}

MACIÁ-BARBER, Carlos (2015): “La posibilidad de implantar un estándar ético en la empresa periodística española: percepción de los directivos de los medios". Estudios sobre el Mensaje Periodístico. Especial noviembre "Periodismo e información de calidad", págs.: 119-134. Madrid, Servicio de Publicaciones de la Universidad Complutense.

Sumario: 1. Crisis económica, periodismo y deontología. 2. Iniciativas incipientes para certificar el proceder ético de la empresa periodística; 2.1. El sello ético como contraste deontológico; 2.2. Certificaciones de calidad para medir la eticidad de los medios. 3. Objeto, objetivo e hipótesis. 4. Metodología. 5. Resultados; 5.1. Palpable desafecto por un certificado de calidad ética para los medios en España; 5.2. Bondades y deficiencias que se atribuyen a la certificación; 5.3. Las variables básicas a medir por una certificación ética periodística; 5.4. Demanda del juicio de expertos en un organismo profesional independiente. 6. Conclusiones y discusión. 7. Referencias bibliográficas. 


\section{Crisis económica, periodismo y deontología}

Resulta coincidente la opinión de los profesionales de la comunicación españoles sobre los conflictos contemporáneos presentes en el ejercicio del periodismo, en cuanto a la naturaleza de las dificultades y estadios de gravedad de los problemas, a tenor de los resultados que arrojan investigaciones de análogo planteamiento, magnitud y propósito realizadas en el último quinquenio (Maciá-Barber y Herrera, 2010: 51; Asociación de la Prensa de Madrid, 2012: 37 y 2013: 38; Figueras et al., 2012: 72 73; Servimedia, 2012; Maciá-Barber, 2014: 24).

La precariedad y la inseguridad laborales constituyen la dificultad cardinal. En su declaración con motivo del Día Internacional de la Libertad de Prensa de 2014, la Asociación de la Prensa de Madrid (APM) alertaba de que la crisis económica ${ }^{1}$ ha causado en el sector periodístico español el debilitamiento de la independencia de la empresa informativa. La APM instó a editores y directores de medios a que mejorasen la situación laboral y salarial de los empleados, sobre todo de los colaboradores y los free lance, obligados a trabajar en condiciones de indefensión y con tarifas humillantes. Y solicitó al Ministerio de Empleo y Seguridad Social que reforzara las inspecciones a las compañías que vulneran el derecho constitucional al trabajo remunerado ${ }^{2}$.

Los profesionales alertan asimismo del predominio en los medios de los intereses particulares de los poderes económicos (corporaciones, anunciantes, accionistas...) y las ambiciones propias de la política (Gobiernos, partidos políticos...), frente al interés general de la ciudadanía que debería prevalecer.

La combinación de estas tendencias - la severa crisis económica, la explotación laboral y las indebidas injerencias externas- probablemente expliquen que la tercera de las preocupaciones del colectivo sea el desprecio a la autonomía del profesional de la información, al que se atenaza en el desempeño de su función, como advierte la APM: periodistas sometidos a la creciente presión de los poderes, ávidos de convertir la información en propaganda, la crítica en elogios, la información en desinformación. En consecuencia, esta sumisión supondría un claro indicio de que se coarta la libre expresión del intermediario que administra un derecho fundamental que posee todo ciudadano.

Afloran igualmente las fisuras éticas. De un lado, queda patente la denuncia de una baja conciencia de la responsabilidad social del periodista, exigencia inherente al desempeño informativo, que se transmuta en la percepción de una inequívoca falta de ética en el quehacer profesional. En el marco empresarial, se menciona la correlación, en apariencia antinómica e insoluble, beneficios versus ética (Chillón, 2011), un

1 Desde 2008, 11.151 empleos se han perdido en España y 284 medios desaparecieron. En 2013, se destruyeron 4.434 puestos de trabajo y cerraron 73 empresas (APM, 2013).

2 El 23 de enero de 2012, con motivo de la celebración del patrón de los periodistas, San Francisco de Sales, la APM hizo pública la declaración por un trabajo digno \#gratisnotrabajo, etiqueta que ha calado en las redes sociales para denunciar aquellas ofertas de trabajo indignas que persiguen que los periodistas ejerzan gratis, para reclamar que sean investigadas $y$, si procede, que se sancionen. 
sustrato que abona el desprestigio social del gremio. En la escala institucional, el grado de confianza de la población española en los medios resulta sin duda insuficiente $-4,51$ sobre 10, constata el Centro de Investigaciones Sociológicas (CIS), 2014-, siendo la de periodista la segunda profesión más denostada (CIS, 2013).

Tanto el fenómeno de la concentración empresarial en torno a grandes corporaciones multimedia, como la progresiva convergencia digital provocan la homogeneización y el sacrificio de los contenidos: se persigue el máximo rendimiento y el beneficio a toda costa. En tiempos en los que prima la ganancia, la aceptación del producto periodístico por las audiencias acaba por convertirse en el criterio prioritario en la producción, con independencia de la calidad, de lo fundamentado o acertado que sea el sistema de medición, o de lo fundado del criterio de la ciudadanía. La reorganización de la producción y la naturaleza del producto periodístico sustentada en los intereses de accionistas y propietarios para afrontar malos resultados económicos trasmutan, sin justificación, la naturaleza del negocio. Dos casos recientes a escala internacional que, aunque foráneos, resultan vigorosamente ilustrativos. El primero, la portada que publicó el rotativo francés Libération ${ }^{3}$, cuando los redactores se rebelaron contra el proyecto empresarial de reconvertir al diario en una red social, creadora de contenidos, un cometido - alegaron- alejado de su oficio y sus valores; el segundo caso, aconteció en Le Monde: las renuncias de siete redactores jefe, que denunciaban una deriva de la línea editorial y cuestionaban una reorganización interna de personal originada por los intereses empresariales personales de uno de los tres accionistas del rotativo, desembocaron una semana después en la dimisión de Natalie Nougayrède, la directora de la publicación, elegida para el cargo poco más de un año antes con el $80 \%$ de los votos favorables de la redacción.

¿Acaso es prioritario, siempre y en toda ocasión, el beneficio económico? ¿Ha de prevalecer la subsistencia del proyecto empresarial a cualquier precio? ¿Es rentable la ética? ¿Debe quedar la deontología en un segundo plano? Son estos interrogantes clásicos sobre los que, en el caso presente, interesa profundizar de la mano y la experiencia de los propios directivos que gestionan las corporaciones periodísticas españolas.

\section{Iniciativas incipientes para certificar el proceder ético de la empresa periodís- tica}

Entre los actuales mecanismos de autorregulación ética que podrían articularse en España figura un estándar específico - o un sello ético- que acreditará la calidad de la organización y de la producción informativa del medio. Este modelo es un patrón

3 El 8 de febrero de 2014, junto a la preceptiva cabecera y un faldón publicitario, ocupó la portada de Libération la siguiente advertencia: "NOUS SOMMES UN JOURNAL pas un restaurant, pas un réseau social, pas un espace culturel, pas un plateau télé, pas un bar, pas un incubateur de starp-up... Les salariés de «Libération» répondent au projet des actionnaires" ["SOMOS UN PERIÓDICO, no un restaurante, ni una red social, ni un espacio cultural, ni un plató de televisión, ni un bar, ni una incubadora de starp-up... Los empleados de "Libération" responden al proyecto de los accionistas"]. 
original apenas implantado todavía que se orienta a someter a la empresa informativa y sus productos a un compromiso ético público continuado.

\subsection{El sello ético como contraste deontológico}

El juez Leveson, en su informe orientado a regenerar la prensa del Reino Unido tras el "escándalo News of the World", que se publicó en noviembre de 2012, recogía en su recomendación trigesimoquinta una prescripción que contemplaba que el futuro nuevo organismo regulador británico, entre sus incentivos de afiliación para los medios, debía estudiar la instauración de un sello que pudieran emplear sus miembros como una marca pública de reconocimiento de un periodismo de confianza (Leveson, $2012)^{4}$.

No se trata, empero, de una propuesta por entero original. En los Estados Unidos, el TAO of Journalism (Transparent, Accountable, Open), auspiciado por el Washington Press Council, constituye un precedente de singular interés. John Hamer, su presidente, lanzó de manera informal la propuesta en la Universidad de Washington (Seattle), en enero de 2010, como proyecto que venía madurando desde un par de años atrás. La iniciativa se sustenta en el lema "A promise to your audience that you will be Transparent about who you are, Accountable for your mistakes, and Open to other points of view".

Los tres puntales en que se asienta este modelo son la transparencia sobre la propiedad del medio y los intereses que pueda albergar y a los que sirve; la responsabilidad sobre los resultados de su labor y la rauda rectificación de los errores en que incurra; y su apertura a la multiplicidad de puntos de vista forjada por una participación activa de las audiencias.

La finalidad de este compromiso público es obtener credibilidad y generar confianza mediante la exhibición del que denominan "sello TAO", exhibiéndolo en la página, pantalla y portal web o blog de reporteros, periodistas ciudadanos o bloggers especializados 5 . El "sello TAO" supone una propuesta de compromiso en cierto modo voluntarista, puesto que no existe una supervisión interna ni externa organizada y sistemática que garantice el grado de respeto de los principios éticos y profesionales que se asumen, salvo la valoración que de la observancia de la deontología formule la ciudadanía: una especie de crowdsourcing ético. Tildo de voluntaristas esta clase de propuestas, no en sentido despectivo, sino propio: una actitud que funda sus previsiones más en el deseo de que se cumplan que en sus posibilidades reales. Cuando se constatara una sistemática violación de los principios éticos que rigen el periodismo, se estipula que los restantes asociados TAO pueden estudiar y valorar la posibilidad de revocar el sello al medio o la persona infractores.

En España, se propugna la creación de un "sello ético" encaminado, por ejemplo, a luchar contra la bautizada telebasura. Este reconocimiento se otorgaría a las em-

4 "A new regulatory body should consider establishing a kite mark for use by members to establish a recognised brand of trusted journalism" (Part K. Chapter 4, paragraph 5.41).

5 El directorio de personas e instituciones asociados abarca compromisos individuales, medios de comunicación y asociaciones estudiantiles (http://taoofjournalism.org/directory). 
presas que pactasen renunciar u oponerse a la emisión de contenidos de "basura-televisiva" y podría incorporarse a la publicidad de marca y sus productos (López y Bordonado, 2007: 322-323).

La experiencia más representativa, de similar denominación aunque no idéntico propósito, es el "segell de compromís ètic" (sello de compromiso ético) de la Fundación del Consejo de la Información de Cataluña (FCIC) ${ }^{6}$. El 23 de julio de 2013 se presentó en Barcelona la iniciativa ${ }^{7}$ cuyo objetivo es que todos los medios comprometidos con el cumplimiento del Código Deontológico de los periodistas catalanes dispongan de un distintivo público que lo acredite y que representa "la voluntad renovada de periodistas y medios de informar de modo veraz, honesto, independiente y al servicio de la ciudadanía" más de 80 empresas y asociaciones vinculadas al mundo de la información en la Comunidad Autónoma de Cataluña miembros del organismo.

El sello supone un reconocimiento a la tarea de los medios, que pueden reforzar su credibilidad ante la ciudadanía. Para su obtención, las empresas han de estar adheridas a la FCIC y al corriente de pago de la correspondiente cuota, asumiendo los siguientes compromisos: a) observar las normas éticas de la profesión, en especial el Código Ético del Colegio de Periodistas, en el desempeño de su función informativa; b) adquirir el compromiso ante la opinión pública de respetar las citadas normas éticas; c) publicar o difundir las resoluciones del CIC que les afecten, a través de la publicación o el programa objeto de una reclamación o de una actuación de oficio; d) insertar el logotipo distintivo del sello en lugar visible del medio y de su web, y difundirlo entre los destinatarios de la información.

El sello puede ser revocado por el plenario del CIC, previa instrucción del correspondiente expediente con audiencia al medio afectado, si observa algunas de las siguientes circunstancias: a) infringir dos o más veces durante el año natural el Código Deontológico, mediando resolución del CIC; b) incumplir alguno de los requisitos adquiridos al recibir el sello; c) que el CIC estime que una determinada actuación del medio ha supuesto una conducta grave contraria al Código Deontológico que justificaría que se desposea al medio del sello. Cuando el CIC revoque el sello, decisión

6 Esta institución de autorregulación periodística se fundó en 1997 en defensa del ejercicio de un periodismo ético y de la libertad de expresión. Desde entonces ha tramitado más de 600 quejas de la población cuando esta consideraba que se había vulnerado el código ético de la profesión periodística de Cataluña.

7 El patronato de la FCIC, en sesión del 18 de octubre aprobó la creación de un sello de calidad, acuerdo reflejado en el artículo 5, apartado f) de los Estatutos de la FCIC aprobados por dicho patronato el 22 de octubre de 2012.

8 "Dado que la información es uno de los pilares de la democracia, la obligación de los periodistas es actuar con veracidad y explicar de manera profesional y coherente los hechos y asuntos de la actualidad. Los medios de comunicación adheridos al Consejo de la Información de Cataluña dispuestos a trabajar de acuerdo con estos criterios, podrán mostrar a sus lectores, televidentes y oyentes, su dedicación y comportamiento mediante la adopción de este sello" [Traducción del catalán del autor]. 
que puede recurrirse, el medio podrá pedirlo pasados dos años desde la resolución de revocación.

Más allá de explicitar la voluntad de un compromiso público con el quehacer ético, este sello no introduce, en realidad, novedad sustantiva alguna, pues su principal bondad es coadyuvar al cumplimiento de un código deontológico ya existente así como a respetar la normativa vigente en relación con el derecho de rectificación.

\subsection{Certificaciones de calidad para medir la eticidad de los medios}

Aunque no específica de la esfera de la comunicación, una interesante experiencia, netamente española y pionera en Europa, es la norma SGE21: 2008, de Forética ${ }^{9}$. Esta certificación supone el primer sistema de gestión de la responsabilidad social europeo que permite, de manera voluntaria, auditar procesos y alcanzar una certificación en Gestión Ética y Responsabilidad Social Empresarial (RSE). Esta certificación parte de modelos ya consolidados como son los de calidad y de medioambiente, que enriquece gracias a una visión multistakeholder ${ }^{10}$. De esta manera, sistematiza las relaciones de la empresa con nueve diferentes áreas de gestión, para las que establece criterios que son desarrollados por un Código de Conducta y supervisados por un Comité de Ética. Las áreas de observación son: alta dirección, clientes, proveedores, integrantes de la organización, hábitat social, entorno ambiental, inversores, competencia y administraciones públicas.

Cabe pensar en ciertos beneficios teóricos de esta certificación. En primer término, operaría para mostrar a los diferentes grupos de interés el compromiso real de una corporación con la gestión de la RSE, fortaleciendo la imagen externa de esa empresa. En segundo lugar, el sostenimiento de la certificación, que ha de superar cada año auditorías externas, contribuiría a la mejora continuada de los procesos y actividad de la organización y coadyuvaría a nutrir la responsabilidad, compromiso y motivación de los equipos humanos implicados. En un tercer nivel, la certificación reduciría la desconfianza social y ampliaría las oportunidades de mercado, atrayendo y fidelizando a clientes, proveedores, empleados e inversores. No obstante, resulta hondamente significativo que hasta el presente solo una empresa española se haya acreditado: MediaResponsable (2011) (www.corresponsables.es), una institución que desarrolla actividades diversas sobre el mundo de la comunicación (estudios, jornadas, conferencias, publicaciones), pero que no es en sentido estricto un medio de comunicación.

9 Forética (www.foretica.org) es la asociación española de empresas y profesionales de la responsabilidad social empresarial cuya misión es fomentar la cultura de la gestión ética y la responsabilidad social dotando a las organizaciones de conocimiento y herramientas útiles para desarrollar con éxito un modelo de negocio competitivo y sostenible. La integran más de 140 organizaciones y más de 100 socios personales. En su seno conviven empresas de todo tamaño y parcela de actividad, además de asociaciones profesionales, organizaciones del tercer sector o académicos de reconocido prestigio.

${ }^{10} \mathrm{El}$ concepto stakeholder alude a cualquier persona o entidad que es afectada o concernida por las actividades o la marcha de una organización (trabajadores, accionistas, asociaciones vecinales afectadas, sindicatos, organizaciones civiles y gubernamentales vinculadas, etc.). 
La experiencia más compleja en el campo de la certificación la sustenta la organización no lucrativa suiza Media and Society Foundation ${ }^{11}$, que ha desarrollado en Europa certificaciones $\mathrm{ISO}^{12}$ destinadas de modo específico a las empresas periodísticas. Estos patrones universales de gestión de calidad de los medios son las normas ${ }^{13}$ ISAS BC 9001 (2003) para la televisión, radio e Internet y la ISAS P 9001 (2005) para medios impresos, refundidas en el estándar ISAS BCP 9001:2010, cuyo eje de evaluación es la contribución de un medio al desarrollo de la democracia y de la sociedad.

La certificación no mide programas o mensajes específicos puntuales que se emiten o publican, sino que evalúa al medio en su globalidad, en su capacidad para producir una programación de calidad y servir de modo apropiado a la sociedad. Fruto de un estudio de campo en cinco países -Canadá, Colombia, India, Sudáfrica y Suizase fijaron como puntos cruciales de evaluación ISO para medios una serie de variables: la independencia y la transparencia, la ética, el reconocimiento de las identidades culturales, la accesibilidad de los medios, la innovación y la creación, la relevancia social y la calidad de los contenidos, el pluralismo y la apertura al mundo. Desde el 1 de junio de 2012, Société Générale de Surveillance (SGS), líder mundial en inspección, verificación, ensayos y certificación se encarga de todos los mandatos de certificación incluyendo auditorías de seguimiento. La obtención de la certificación demora entre 9 y 18 meses.

El análisis de la lista oficial de empresas certificadas hasta el presente muestra una notoria ausencia de medios de referencia internacional y de grandes corporaciones periodísticas, al tiempo que su nula presencia en naciones relevantes de las diversas culturas periodísticas ya consolidadas. Esta débil aparición apunta a una endeble implantación del modelo e invita a dudar de la operatividad futura del modelo.

A escala internacional existe otra valiosa iniciativa de gestión de la calidad, específica para el ámbito de la comunicación: el Sustainability Reporting Guidelines Media Sector Supplement (mayo, 2012), impulsado por Global Reporting Initiative ${ }^{14}$ (GRI),

11 "The Media and Society Foundation is implementing a universal media quality management standard implying, among other things, quality control in the newsroom. We are a group of mostly retired media professionals working on a voluntary basis out of the conviction that society needs stronger media and that media will only be stronger if they become more transparent, more accountable and more efficient", reza en su portal oficial (www.media-society.org).

${ }^{12} \mathrm{La}$ International Organization for Standardization (ISO) desarrolla y publica los estándares internacionales. Entre los más populares figuran el ISO 9001:2008 (gestión de calidad) y el ISO 26000:2010 (responsabilidad social).

${ }^{13}$ Basadas en la norma ISO 9001, un sistema de gestión de la calidad fundado en el ciclo de mejora constante: planificar, desarrollar, comprobar y actuar.

${ }^{14}$ Organización sin ánimo de lucro, fundada por CERES y el Programa de las Naciones Unidas para el Medio Ambiente en 1997 en Estados Unidos. Su fin es impulsar la elaboración de memorias de sostenibilidad en toda clase de organizaciones. La institución mantiene alianzas estratégicas globales con la Organización para la Cooperación y el Desarrollo Económico (OCED), el Programa de las Naciones Unidas para el Medio Ambiente (PNUMA), el Pacto Mundial de las Naciones Unidas (United Nations Global Compact, UNGC) y la Organiza- 
con el apoyo de la Fundación Avina, la Fundación para el Nuevo Periodismo Iberoamericano (FNPI) y la Universidad Javeriana. En la actualidad se trabaja en la versión G4, que mejoraría la actual (G3.1). El proceso del "Grupo de Trabajo del Suplemento del Sector de los Medios", coordinado por la FNPI, se desarrolló de diciembre de 2009 a diciembre de 2011, involucrando a 20 representantes de compañías y grupos mediáticos, y organizaciones ambientales, laborales y no gubernamentales (The Guardian, BBC, Bertelsmann, Vivendi, Clarín, Warner Brothers, The Nature Conservancy, ANDI Comunicación y Derechos, la Federación Internacional de Periodistas y Transparencia Internacional).

En conjunto, la mayoría de experiencias del GRI se concentran en Europa y América, en especial en aquellas naciones que cuentan con cierta tradición de mecanismos de autorregulación periodística, sean públicos o privados (consejo de prensa, ombudsman, códigos deontológicos), tales como Estados Unidos, Sudáfrica, Francia, Finlandia, Alemania, Países Bajos, España, Brasil o Colombia. Estados Unidos lidera esta iniciativa por número de compañías evaluadas (9) y se sitúan en cabeza a escala mundial España (6), Brasil (6) y Sudáfrica (6).

La guía contempla una tríada de contenidos básicos: a) el contexto general de la comprensión del cometido de la organización (estrategia, perfil, estructura, gobierno corporativo, enfoque de la dirección); b) enfoque de la gestión (cómo la organización aborda un determinado conjunto de aspectos para contextualizarlos); y c) indicadores de práctica: económicos, medioambientales, sociales (prácticas laborales, derechos humanos, sociedad y responsabilidad de producto).

Este modelo de certificación, a diferencia de los anteriores, permite conjugar y tasar al tiempo el doble perfil y propósito que entraña toda empresa periodística, gracias la evaluación de la transparencia de la propiedad y de los fines de la corporación, el análisis deontológico del ejercicio profesional periodístico real y de la evaluación de los indicadores estrictamente económicos y éticos de la organización productiva.

\section{Objeto, objetivo e hipótesis}

El objeto del estudio es enjuiciar la posibilidad de implantar un específico estándar ético en la empresa periodística española, conforme a la percepción de los editores, directivos y mandos intermedios de las principales corporaciones mediáticas por relevancia y por difusión en prensa, radio, televisión y medios digitales.

El objetivo era dar cumplida respuesta a cuatro cuestiones primordiales:

1. Para los directivos de los medios, ¿tiene sentido otorgar una certificación de calidad de ética específica para la empresa periodística española?

2. ¿Cuáles serían para ellos las bondades y deficiencias de esta certificación?

3. En su opinión, ¿qué aspectos concretos debería contemplar la certificación?

4. Según su parecer, ¿quién debería otorgarla?

ción Internacional de Normalización (ISO). GRI y su "Guía para la elaboración de Memorias de Sostenibilidad" actúan en sinergia con la Iniciativa de la Carta de la Tierra, la Corporación Financiera Internacional (CFI) y la Conferencia de las Naciones Unidas sobre Comercio y Desarrollo (UNCTAD). 
En consonancia con las cuestiones planteadas, las cuatro hipótesis que se buscó comprobar o refutar fueron las siguientes:

H1: Los directivos creen que sí tiene sentido una certificación específica de las prácticas éticas en el marco de la empresa informativa.

H2: Entre las bondades del modelo se destacarán la mejora de la imagen del colectivo periodístico y, en especial, de la propia compañía. Entre las deficiencias, la dificultad de su implantación real y efectiva.

H3: Existe una notable variedad y divergente valoración de las variables que deban integrar una certificación ética de las corporaciones informativas.

H4: Los directivos apuestan de modo prioritario por un reconocimiento de la sostenibilidad ética de la empresa periodística que se organice y otorgue desde el colectivo profesional.

\section{Metodología}

Estos objeto, objetivo e hipótesis se contemplan en un proyecto nacional de I+D+i de la Universidad Carlos III de Madrid denominado "Deontología y excelencia informativa: implantación y consolidación de prácticas éticas en la empresa periodística" (CSO2010-15575/COMU), financiado por el Ministerio de Economía y Competitividad de España (2011-2014).

Un empeño crucial de la propuesta era averiguar el discurso en profundidad y la percepción de los responsables de las corporaciones periodísticas en torno a la crisis ética de las empresas del sector, sus causas y sus consecuencias. Para alcanzar este propósito se utilizó una triangulación de técnicas cualitativas y cuantitativas que permitieran trazar con el mayor detalle el estado de la cuestión y aquilatar datos específicos procedentes de este colectivo.

Resultó complejo abordar una realidad de la que, de inicio, se desconocía la magnitud exacta del colectivo involucrado. La inexistencia de censos actualizados de los medios y la ausencia de una colegiación obligatoria en España impiden de facto disponer de cifras concretas. A finales de 2011 se estimaba entre 20.500 y 24.500 el número de periodistas ejercientes en empresas informativas, y en torno a 8.000 los que prestaban sus servicios en gabinetes de prensa de la Administración del Estado. En esa fecha, el número de licenciados en Periodismo ascendía a 75.000, aunque solo un porcentaje se dedicaba a esta actividad, y parte de quienes se empleaban, poseían otras formaciones. Por tanto, no podía determinarse la cifra precisa de responsables y directivos de los medios, máxime cuando un porcentaje significativo de los mismos cuenta, además, con formación y experiencia profesional ajenas al campo de la comunicación. En consecuencia, en el proyecto primó la investigación cualitativa.

El trabajo de campo cualitativo se estructuró en dos fases ejecutadas de forma simultánea (enero-junio de 2012): realización de entrevistas semiestructuradas en profundidad $(n=30)$ y el desarrollo de grupos focales de discusión $(n=3)$. Para las entrevistas se procuró que los sujetos representasen al grueso de la profesión periodística, incluyendo medios públicos y privados, así como agencias de noticias, diarios, revistas, cadenas de televisión, emisoras de radio y medios digitales. Los opinantes, una treintena de altos cargos seleccionados por el interés y la profundidad de su dis- 
curso, y por la relevancia histórica y económica de sus empresas ${ }^{15}$, encarnan una equilibrada representación de los niveles directivos en los medios (presidente, consejero delegado, director, director general, director adjunto, subdirector, director de comunicación, responsable de responsabilidad corporativa) y cargos de responsabilidad profesional (director de informativos, editor, redactor jefe, defensor del lector). En el caso de los tres grupos de discusión (mayo-junio 2012), participaron 22 personas $^{16}$.

Por su parte, para la investigación cuantitativa el universo de la muestra estuvo integrado por comunicadores residentes en la Comunidad Autónoma de Madrid (CAM) y empleados de empresas periodísticas radicadas en la misma región, mediante un muestreo aleatorio simple. Se obtuvo una respuesta representativa de cuestionarios válidos ( $\mathrm{n}=420)$. El 77,6\% de los encuestados contaba con formación superior en Ciencias de la Información (licenciatura o doctorado).

\section{Resultados}

En consonancia con la hipótesis de partida, el sujeto principal de observación directa fueron los miembros de la gerencia y con cargo de responsabilidad en las organizaciones -directivos y mandos intermedios ${ }^{17}$ - en la medida en que desempeñan un papel predominante en el afianzamiento de las líneas editoriales y, por consiguiente, de los criterios informativos que se derivan de las mismas, así como de la organización, la administración y el control de la entidad.

\subsection{Palpable desafecto por un certificado de calidad ética para los medios en Es- paña}

En el colectivo de directivos y propietarios de los medios españoles existe una perceptible división ante la implantación de una certificación de calidad ética para las empresas informativas.

${ }^{15}$ Los medios o grupos empresariales representados, por soportes, fueron: prensa (20minutos, Actualidad Económica, As, Cinco Días, El Mundo, El País, Interviú, La Razón, La Vanguardia, Marca, Prisa, Unidad Editorial), radio (Abc Punto Radio, Cadena COPE, Cadena SER, Onda Cero, Onda Madrid, Radio Nacional de España), televisión (Antena 3 TV, Intereconomía TV, Mediapro, Telecinco, Telemadrid, Televisión Española) y digital (El Confidencial, Estrella Digital, lainformacion.com, sijuntos.com), así como agencias de información (Agencia Efe, Europa Press, Servimedia).

${ }^{16}$ Los medios y grupos participantes fueron Abc Punto Radio, El Mundo Financiero, El Siglo, Documentación de Medios, FORTA, Luike, Crónica Popular, Servimedia, Actualidad Económica, AR, La Sexta, Marca, Qué!, RNE (Radio 5), sijuntos.com, Cadena COPE, RTVE, Dircom, El Pais, Prisa Radio y Vocento. Participaron 22 directivos, con el siguiente perfil: a) sexo: hombre (59\%), mujer (41\%); b) edad: 49,3 años; c) formación: licenciatura o doctorado en periodismo $(86,4 \%)$, otras $(13,6 \%)$; d) cargo: presidente $(4,5 \%)$, director general $(36,4 \%)$, subdirector $(4,5 \%)$, director $(18,2 \%)$, director comunicación $(18,2 \%)$, otros $(18,2 \%)$; f) experiencia laboral: ocupación media $(27,0$ años). En prensa $(11,4)$, radio $(6,6)$, televisión $(2,3)$, Internet $(2,6)$, gabinete de prensa $(2,3)$, agencia $(1,8)$.

${ }^{17}$ Los cargos de los sujetos entrevistados eran: presidente (6), director/consejero delegado (13), subdirector (1), director de informativos/editor (4), director de Comunicación/RSE (3), redactor jefe (2) y defensor del lector (1). 
Entre los pilares que justificarían su existencia, los partidarios señalan el conferir credibilidad a la empresa ante el ciudadano y el representar una ventaja comparativa frente a la competencia. De igual modo, no se oculta que este sistema coadyuvaría a defender al trabajador ante la compañía. Y se apunta que los medios que ya poseen iniciativas de autorregulación accederían con más facilidad a una supervisión movidos por su querencia a la transparencia.

No obstante, los proclives a la certificación, aun cuando reconocen que es una interesante meta que alcanzar, alegan lo complejo que resulta materializar ese proyecto. Entre los obstáculos que perciben figura la necesidad de negociar el modelo a aplicar entre los estamentos implicados, pues, advierten, existe desinterés -cuando no radical oposición- por todo cuanto huela a control externo, y existe evidente desunión en una profesión dominada por los intereses particulares, se argumenta. De igual modo, se indica la dificultad para aceptar en la práctica los resultados de una verificación ("existe desafección cuando nos va mal", se apunta). Tampoco faltan reacciones de sorpresa ante la propuesta, para algunos un signo de novedad, pero que suscita diversidad de posturas, desde el escepticismo al miedo.

Casi la mitad de los entrevistados confiesa su desafección por un modelo de certificación o un sello ético, negativa que asienta en una tríada de motivos.

Una poderosa línea argumental avanza por la intricada senda de la valoración. Entre los argumentos esgrimidos, el manido pero tangible de otorgar el dictamen a la audiencia (satisfacción, elección, gusto...), porque la autorregulación sería cosa de la conciencia de cada profesional. Se alude, no pocas veces, a la inexistencia de algo o alguien que pueda situarse de facto "más allá del bien y del mal", o bien se considera que sería una especie de tribunal orientado a un arriesgado sistema de concesiones solo a quien se calificase ético desde el poder político. $\mathrm{O}$, por lo general, se arguye que la legislación informativa actual es suficiente, aunque bien podría progresar en agilidad y en la formación especializada de los jueces, como sucedió con anterioridad en otros ámbitos (violencia de género, tráfico).

En segundo término, se apela al mismo proceso técnico de evaluación, pues se estima imposible disponer de una metodología de análisis suficientemente válida o se niega que la medición pueda ser objetiva, por cuanto siempre estaría contaminada por un juicio moral, ético o ideológico. Es inviable, por ejemplo, "porque toda empresa periodística posee ideología", que no puede valorarse mediante un sello de calidad. Lograr una metodología que sustentara esa clase de certificación supondría "un juego apasionante y divertido", se apostilla con ironía.

En definitiva, asoma en el discurso el sempiterno dilema de la subjetividad en el quehacer periodístico, donde no cabe aplicar fórmulas matemáticas que solucionen de manera unívoca los retos profesionales, debido a la naturaleza del producto: "No somos una lata de alubias", se protesta; ni cabe, por analogía, establecer un ranking de "estrellas Michelín".

Y no falta la alusión a la combatividad: se acabaría por dar la certificación a todos porque, de lo contrario, quien no la recibiera, impugnaría el sistema por considerarlo injusto, o por entender que perjudica a su empresa o, simplemente, lo desacreditarían. En última instancia, de hecho, se apela al prestigio social: "The New York Times carece de sello de calidad", se recalca. 
En paralelo, para contrastar resultados, se consultó mediante un cuestionario online a los restantes profesionales participantes en el estudio. La valoración media de la propuesta fue de 6,4 sobre 10 . Una aceptación mayoritaria $(76,7 \%)$, aunque no exenta de reticencias a este posible mecanismo de promoción de la ética periodística. No existen amplias disparidades en la valoración en función de la categoría y las funciones profesionales, si bien el personal de base y los empleados ajenos a la gestión y la dirección concedieron una puntuación ligeramente superior (la diferencia es de $0,2)$.

\subsection{Bondades y deficiencias que se atribuyen a la certificación}

Desde una aproximación apriorística, los directivos desentrañan los pros y contras de un posible sistema de certificación ética periodística. Los partidarios aluden a que podría fortalecer el prestigio de la empresa, generando incluso rentabilidad en inversión publicitaria. De ahí, que un incentivo innegable para su implantación sería el constituir un aval de calidad, muestra del trabajo bien hecho, que posibilitaría, por ende, la creación de una clasificación de desempeño ético de los medios que facilitaría conocer las fortalezas y debilidades de la competencia. Y, de paso, quizá salvar la susceptibilidad profesional que aprecian en el sector propietarios y directivos.

Por contra, las deficiencias que se subrayan son el riesgo de generar una mera política de imagen, con una amenaza latente: instrumentalizar la iniciativa gracias a inversiones en campañas para presionar al órgano inspector y, con posterioridad, tras conquistarlo, rentabilizar el sello.

Otro déficit que se apunta con frecuencia se fundamenta en el ingente trabajo que implicaría mantener el sistema, que quizá acabaría por requerir el concurso de la Administración, con la consiguiente pérdida de independencia. Sin olvidar la posible influencia ideológica que, se insinúa, teñiría la evaluación. Lo que sustentaría la sugerencia de algunos responsables de reconvertir la propuesta en un premio.

La restringida capacidad sancionadora-moral, como en el caso del ombudsman de prensa- que aprecian los directivos podría potenciarse, defienden, si se publicitan las resoluciones que se adopten, así como se fijan sanciones económicas.

Finalmente, un inconveniente es la desnaturalización de ciertos sellos en otros sectores, desprestigio contagioso, y el hecho de que la proliferación de certificaciones provoque su pérdida de valor por considerarlos una moda ("hay tantos que al final...").

\subsection{Las variables básicas a medir por una certificación ética periodística}

En realidad, los directivos, en su conjunto, acaban por citar probablemente todas las posibles variables que bien podrían integrar esa futura certificación o sello. De manera reiterada se citan, en buena lógica, como era de prever, el respeto de los códigos deontológicos periodísticos y de las normas internas profesionales asentadas desde antaño (off the record, ecuanimidad, contraste informativo, relación con las fuentes...), así como de los contenidos que se difunden (veracidad, equilibrio).

Sin olvidar, por otro lado, el funcionamiento interno de la empresa, de modo que se estime la adecuación de los actos propios con la prédica pública (transparencia de la propiedad, política de personal, contratación publicitaria, respeto medioambiental). 
En el tercer escalón, aparecen los aspectos legales, como el respeto de los valores democráticos, la defensa de los derechos humanos, así como la observancia de la propiedad intelectual. Lo que sustentaría, llega a proponerse, el contabilizar las sanciones acumuladas por cada medio, incluso para elaborar una clasificación pública de incumplimientos.

\subsection{Demanda del juicio de expertos en un organismo profesional independiente}

Frente a una anecdótica opción por lo privado contabilizada, se demanda sistemáticamente que se encargara del certificado o sello un organismo público, no de la Administración porque debe ser independiente, rasgo reiterado hasta la saciedad. El tejido empresarial no debiera ser juez y parte, por lo que se encomendaría a los colegios profesionales de periodistas o asociaciones de la prensa que delegarían en un grupo de expertos el análisis de los parámetros objeto de estudio. En este sentido, se propugnan instituciones ya existentes, como la Comisión de Arbitraje, Quejas y Deontología del Periodismo de la Federación de Asociaciones de Periodistas de España (FAPE), u otras aún por constituirse, como el controvertido Consejo Estatal de Medios Audiovisuales. Pese a las reticencias mutuas entre profesión y academia, se aprecia no obstante una posible competencia de la Universidad en el proceso. Cuando se postula, se demanda una evaluación periódica, sin descartar que fuera anual.

A los miembros del posible organismo se les exige a las claras un prestigio intachable y que actúen con criterios eficientes y profesionales. Aunque apenas se aboga por una determinada clase de miembros, salvo abogados o usuarios. Pero aparecen sustanciales dudas, que no son sino inconvenientes: ¿Cómo unificar criterios? ¿Cómo armonizar seguramente integrantes variopintos? ¿Cómo aunar la profesión? Porque, se insinúa, "si en el Tribunal Constitucional pasa lo que pasa...".

\section{Conclusiones y discusión}

Toda investigación científica posee limitaciones inherentes al proceso, que debe valorarse en su contexto histórico, económico, social y científico. La presente no es una excepción.

Los resultados que se presentan se circunscriben a profesionales que ejercen en la Comunidad Autónoma de Madrid y no deben extrapolarse al conjunto de la empresa informativa española. Con todo, hay que significar que las empresas y directivos objeto de la investigación representan, en su conjunto, a los medios y corporaciones informativas de mayor relieve a escala nacional en los diferentes soportes. Por trayectoria histórica, tamaño de la empresa, volumen de negocio y circulación/difusión atesoran, por consiguiente, indudable representatividad.

El proyecto de investigación que sirve de marco se orienta a la transferencial real de resultados desde la Universidad al sector productivo periodístico. Esta virtud podría verse empañada por la tradicional reticencia y alejamiento de los medios en relación al mundo académico, una mezcla de desconfianza, e incluso desprecio, que se percibió en el discurso de parte de los sujetos entrevistados. Por ello, en todo momento, en atención al principio de probidad intelectual se abordó la cuestión sin prejuzgar el quehacer individual de los entrevistados ni el colectivo de los medios en 
relación a sus prácticas deshonestas o incorrectas, de modo que no se ha pretendido evacuar un juicio ético, intención ajena a esta indagación.

El conjunto de los resultados resulta enriquecedor en la medida en que recoge cuantiosas perspectivas y reflexiones, complementarias con frecuencia, que posibilitan aquilatar los argumentos que esgrimen partidarios y detractores de someter al medio en su conjunto a un examen minucioso y riguroso desde la perspectiva de la ética de los negocios y de la responsabilidad social del periodista. Resulta evidente que no existe un criterio unívoco, ni siquiera parejo, en la mayoría de las acreditadas voces que se auscultaron.

La primera hipótesis (H1) apenas se confirmó en parte, pues para un significativo número de directivos una certificación específica de las prácticas éticas en el marco de la empresa informativa carece de sentido y la rechazan de plano, sea por la supuesta imposibilidad de encontrar juez autorizado, sea por considerar que la práctica ética enraíza en cada actor; o bien por presunta imposibilidad metafísica o metodológica para asentar con firmeza el necesario proceso de evaluación. Incluso los partidarios de una certificación, aun cuando confiesan que es una sugestiva finalidad, advierten lo complejo que resulta materializar ese proyecto. Entre los obstáculos, perciben la necesidad de negociar el modelo entre todos los estamentos implicados, pues, previenen, existe desinterés - cuando no radical oposición- por todo cuanto implique un control externo, y existe indudable desunión en un gremio dominado por intereses particulares, argumentan.

Los principales aprietos estribarían, de entrada, en quién otorga la certificación (H4). La repulsa a las compañías del sector es masiva, lo que indica una inequívoca desconfianza en el criterio ético de las empresas: se apuesta de modo prioritario por un reconocimiento de la sostenibilidad ética de la empresa periodística organizado y otorgado por sus iguales, a través de los comités deontológicos de los colegios y asociaciones de periodistas. Combinando las tendencias que se perfilan en las prioridades de los profesionales de la comunicación (asociación profesional, comisión deontológica, Universidad, audiencia), bien podría apuntarse una institución que aúna la representatividad de esos diferentes estamentos, aunque ya posea otros cometidos y no fuera exclusiva para este propósito: la Comisión de Arbitraje, Quejas y Deontología del Periodismo de la Federación de Asociaciones de Periodistas de España (FAPE). Además de poseer una innegable representatividad del sector, y de tratarse de una comisión deontológica, de ella forman parte profesionales de la comunicación con una trayectoria extensa y acreditada; miembros de la Universidad, de fundaciones culturales y sociales, o instituciones cívicas, y de la judicatura. Aunque queda en el aire cómo podría afrontar este organismo tamaña carga de trabajo.

Un segundo escollo sería el determinar los contenidos específicos a valorar (H3). En realidad, los directivos, en su conjunto, citan probablemente todas las posibles variables que bien podrían integrar esa futura certificación o sello. Se citan, en buena lógica, como era previsible, el respeto de los códigos deontológicos periodísticos existentes y de las normas internas profesionales asentadas desde antaño (off the record, ecuanimidad, contraste informativo, relación con las fuentes...), así como de la eticidad de los contenidos (veracidad, equilibrio). Sin olvidar, por otra parte, el fun- 
cionamiento interno de la empresa, de modo que se estime la adecuación del comportamiento propio con el discurso público (transparencia de la propiedad, política de personal, contratación publicitaria, respeto medioambiental). A la par se consideran los aspectos legales, como el acatamiento de los valores democráticos, el defender los derechos humanos y el respeto de la propiedad intelectual. Lo que sustentaría, llega a proponerse, el registrar las sanciones acumuladas por el medio, incluso para componer una clasificación pública de incumplimientos.

En relación con los pros y contras inherentes a la certificación (H2), la principal virtud sería visibilizar los esfuerzos de las empresas periodísticas por alcanzar la excelencia ética y, en segundo término, el cuño serviría de guía para el comportamiento honesto de sus profesionales. En el primer caso, se confirmaría esa hipotética la mejora de la imagen de la colectividad periodística. Pero, al tiempo, en similares proporciones, ciertamente se considera una estrategia de mercadotecnia vacía de impacto ético real.

\section{Referencias bibliográficas}

ASOCIACIÓN DE LA PRENSA DE MADRID (2012): Informe anual de la profesión periodística 2012. Madrid, APM.

ASOCIACIÓN DE LA PRENSA DE MADRID (2013): Informe anual de la profesión periodística 2013. Madrid, APM.

CENTRO DE INVESTIGACIONES SOCIOLÓGICAS (2013): "Barómetro de marzo. Estudio $n^{\circ} 2981$ " en, http://www.cis.es/cis/export/sites/default/-Archivos/Marginales/2980_2999/2981/Es2981.pdf [fecha de consulta: 12 de abril de 2013].

CENTRO DE INVESTIGACIONES SOCIOLÓGICAS (2014): "Barómetro de abril. Estudio n ${ }^{\circ}$ 3021", http://datos.cis.es/pdf/Es3021mar_A.pdf [fecha de consulta: 9 de mayo de 2014].

CHILLÓN, José Manuel (2011): “Ética y empresa informativa: notas para un discurso integrador". Comunicación y hombre, núm. 7, pp. 107-118.

FIGUERAS Mónica; MAURI, Marcel; ALSIUS, Salvador; y SALGADO, Francesc (2012): "La precariedad te hace dócil. Problemas que afectan a la profesión periodística". El Profesional de la Información, vol. 21, núm. 1, pp. 70-76. http://dx.doi.org/10.3145/epi.2012.ene.09

LEVESON, Lord Justice (2012): Leveson inquiry: culture, practice and ethics of the press, http://webarchive.nationalarchives.gov.uk/20140122145147/http:/www.levesoninquiry.org.uk/about/the-report [fecha de consulta: 10 de enero de 2014].

LÓPEZ, Ma del Mar y BORDONADO, Julia (2007): “Telebasura, ética y derecho: límites a la información de sociedad en televisión". En Congreso Internacional de Ética y Derecho de la Información (5 ${ }^{\circ}$. 2007. Valencia): La ética y el derecho de la información en los tiempos del postperiodismo. Valencia, Fundación COSO, pp. 307-324. 
MACIÁ-BARBER, Carlos (2014): "La sostenibilidad ética en la empresa informativa: la percepción y el discurso de los directivos de los medios". Dilemata, núm. 14, pp. 19-35.

MACIÁ-BARBER, Carlos y HERRERA, Susana (2010): Ética y excelencia informativa: los conflictos y retos del quehacer periodístico desde la perspectiva de los profesionales de la Comunidad de Madrid [CD]. Madrid, Asociación de la Prensa de Madrid/Universidad Carlos III de Madrid.

SERVIMEDIA (2012): La ética en la empresa periodística y sus profesionales http:/www.estudiodecomunicacion.com/extranet/portfolio-view/la-etica-en-la-empresa-periodistica-y-sus-profesionales [fecha de consulta: 12 de diciembre de 2013]. 